\title{
THE TRANSVERSAL COMPETENCE "CRITICAL THINKING" IN THE SUBJECT THEORY OF ARCHITECTURE. PROTOCOL AND FIRST ADVANCES OF A PILOT EDUCATIONAL INNOVATION
}

\author{
Lidia García-Soriano \\ Universitat Politècnica de València (SPAIN)
}

\begin{abstract}
This article illustrates a pilot educational innovation, whose main objective has been carrying out several learning activities with students in order to develop the transversal competence of critical thinking and appreciate how they self-perceive their own skill level regarding this specific competence.
\end{abstract}

The activities have been done in a group of 4th year students at the School of Architecture of Valencia, Spain, within the framework of the subject "Theory of Architecture".

The transversal competence of critical thinking is essential in architects' training, at all levels. Theory of Architecture is the foundation from which architectural criticism will subsequently emerge. Comprehend this system of thought can help the students to understand the importance of studying the history and theory of architecture as core subjects for the designing process because they allow the development of the critical thinking that can be, in turn, applied to the design of architecture.

This educational research has attempted to answer two questions, or initial hypothesis: does the case analysis methodology implemented individually and later contrasted in small groups improve students' critical thinking skill? Does it also improve students' self-perception about their own skill level regarding this competence?

This text describes the protocol and the methodology, based both in quantitative and qualitative data analysis, that were used in this pilot activity of educational innovation.

Keywords: Innovation, critical thinking, pilot experience.

\section{INTRODUCTION}

Critical thinking is a transversal competence that is trained specifically in several subjects taught by professors of the Department of Architectural Composition at the School of Architecture of the Universitat Politècnica de València, Spain (ETSA-UPV).

While the research project in hand has been carried out in the framework of the subject "Theory of Architecture" during the 4th year (ETSA-UPV), other subjects, such as "Architectural Composition" during the 4th year and "Architectural Restoration" during the 5th year, could also be incorporated in future educational innovation experiences.

All the mentioned subjects are from the last undergraduate courses (4th and 5th years) which is where the transversal competence of critical thinking is trained at the level 2 of proficiency; for this reason, it would be interesting to take a coordinated action in all of the three subjects.

\section{MOTIVATIONS OF THE INOVATION PROPOSAL}

This project of educational innovation originated from the realization that, in recent years, students often have not adequately developed a critical judgment in the field of architecture, even if the transversal competence of critical thinking is trained in many subjects of the Degree in Fundamentals of Architecture, and is an essential competence in the training of architects, at all levels of mastery.

Theory of architecture, as a specific subject, lays the foundation from which architectural criticism will later be born. Understanding this system of thought can help the students to understand the importance of studying history and theory of architecture as an essential step of the project development, because they inspire the critical thinking that should be applied to the composition and design of actual pieces of architecture [1]. In addition, a particular aspect of architectural theory and criticism is related with heritage and its restoration; therefore it is necessary for the students to 
exercise and train their critical thinking related to architecture in general (historical or contemporary), so that they can later apply the critical thinking to a specific field such as architectural restoration.

As González states that if students are conditioned to think that there is only one, unique and definitive answer, and that the source of this answer is the teacher, it is not surprising that the task of processing the discourse of a theoretical text is, for many students, extremely complex and, consequently, that their motivation towards reading, and analyzing the text is scarce [2].

\section{AIMS OF THE RESEARCH}

The objective of the research is to test an educational innovation that, through a series of learning activities (implementation protocol), is able to improve the transversal competence of critical thinking in $4^{\text {th }}$ year students, while improving also the self-perception of their skill level in this competence.

The question that this research aims to answer is as follow: Does the case analysis methodology done individually and in small groups improve students' critical thinking skills? Does it also improve students' self-perception of their own skill level in this competence?

\section{THEORETICAL BACKGROUND}

The theoretical literature on critical thinking is based on two traditional academic fields: philosophy and psychology [3].

The term "critical thinking" is used to describe the type of thinking that has a clear analytical purpose [4]. The current understanding of this competence is influenced by the research developed by Jean Piaget in the 20s and 30s of the XX century and later by Benjamin Bloom through the introduction of his Taxonomy in 1956 [2].

Since 1980, the Centre and Foundation for Critical Thinking have also promoted the work and study related with this transversal competence, through the publication of books, video guides, events, seminars, courses, professional development programs and a website where it is possible to find many of these digital resources [5] [6].

In 1986, Sternberg highlighted a third scope of application for the critical thinking in the field of education, as a result, different approaches have been historically worked out to define critical thinking according to the method and concerns of each discipline [7]. Some texts, such as Emily R. Lai's, try to organize all this theoretical literature, in these three lines of thought.

To work on the issue of self-perception of critical thinking, literature has also been revised to learn about similar experiences in other contexts, such as critical thinking in the subject of History of Science and Technology [8], self-perception of critical thinking in nursing students [9], or the validation of an instrument to measure the self-perception of this transversal competence in medical students [10].

\section{METHODOLOGY}

In this educational innovation project the methodology combine quantitative analysis (such as the pre and post-test activities regarding the self-perception of critical thinking) and qualitative analysis (such as the final focus group activity). The implementation protocol designed for this educational innovation project is described in detail below.

For the critical thinking self-perception test, a well-known and proven tool such as the MSLQ test by Pintrich et al. 1991 [11] has been chosen. This questionnaire has a specific section of cognitive and metacognitive strategies associated with critical thinking that include 5 questions that are the ones used in this specific the self-perception test.

\section{IMPLEMENTATION PROTOCOL}

The research protocol has been organized in four practical sessions of 90 minutes each, which have been held over the course of the first semester, one session each month approximately; and a shorter final session to assess the experiment qualitatively through a focus group. The following are the learning activities of the protocol. 


\section{1 $1^{\text {st }}$ Practical session $(1,5$ hours $)$}

- Pre-test questionnaire to evaluate students' self-perception of their critical thinking skills (5 min).

- Individual pre-test exercise. Individual critical analysis (small essay) of a short text about architectural theory by an author already analyzed in class. (30-45 min)

- Discussion in small groups (3 students) about the individual critical analysis carried out before (20 min)

- Second critical analysis essay taking into account the contributions of the other students during the discussion (20 minutes)

The evaluation of this exercise by the teacher allows to verify the initial skill level of the students. A specific rubric was designed for the evaluation of the exercise.

\section{$6.22^{\text {nd }}$ Practical session (1,5 hours)}

- Basic explanation done by the professor about the structure of a proper critical analysis applied to the theory of architecture subject. This explanation is complemented by examples taken from the exercises of the $1^{\text {st }}$ session in order to draw attention to the most common errors and correct analysis (30 min).

- Group pre-test exercise. Reading of various theoretical texts in small groups (3-4 students) and preparation of a brief oral presentation about the critical analysis of the texts (30 min).

- Brief oral presentations on the critical analysis made by the group (30 min. 5 min per group, 6 groups).

The evaluation of this exercise is part of the grading of the practical aspect of the course. It is also used by the professor to evaluate the oral expression of the students and obtain further evidence about the learning process of the transversal competence of critical thinking. For the evaluation, an institutional rubric of the ETSA-UPV was used for the oral expression, as well as the same rubric used in the $1^{\text {st }}$ session.

\section{3 $3^{\text {rd }}$ Practical session (1,5 hours)}

- Group post-test exercise. Reading of a short text about architectural theory by an author already analyzed in class and preparing the information to carry out a critical analysis ( $30 \mathrm{~min}$ ).

- Discussion about the text in small groups (3 students) (20-25 min).

- Critical analysis (small essay) taking into account the contributions of the other students during the discussion (30-35 min).

The evaluation of this exercise is part of the grading of the practical aspect of the course. It is also used by the professor to obtain further evidence about the learning process of the transversal competence of critical thinking. For the evaluation, the same rubric of the $1^{\text {st }}$ session was used.

\section{$6.44^{\text {th }}$ Practical session (1,5 hours)}

- Individual post-test exercise. Each student has to choose a theoretical text by one of the contemporary authors explained in class or by another author whose text and works inspire interest in the student $(75 \mathrm{~min})$.

- Brief oral presentations on the critical analysis made by individually.

- Post-test questionnaire to evaluate students' self-perception about their critical thinking skills (15 $\min )$.

The evaluation of this exercise is part of the grading of the practical aspect of the course. It is also used by the teacher to evaluate the oral expression of the students and obtain further evidence about the learning process of the transversal competence of critical thinking. For the evaluation, an institutional rubric of the UPV was used for the oral expression, as well as the same rubric used in the $1^{\text {st }}$ session. The final questionnaire reveals if students' self-perception of their critical thinking skills has improved. 


\subsection{Focus group session (0,5 hours)}

A focus group is established as the final session of this protocol. Since the number of students in the experimental group was small, a brief focus group session in which qualitative data on the experience could be obtained was carried out. Qualitative data analysis is useful because it can highlight some specific issues that can be overlooked among the collected data [12] and that could not be achieved with other methods.
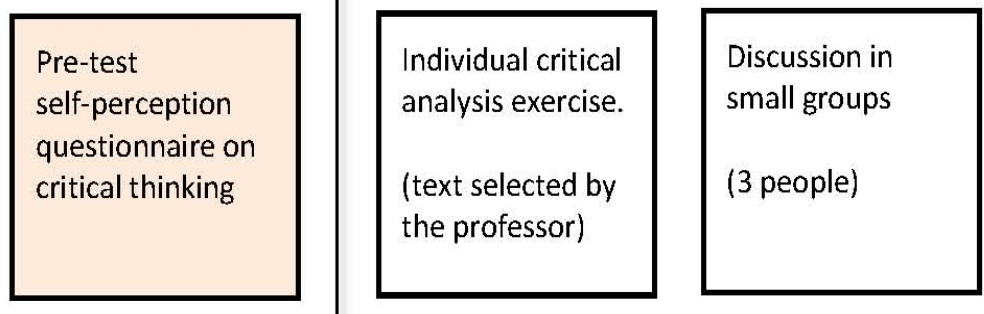

\section{INDIVIDUAL PRE-TEST}

Review of the exercise taking into account the contributions of the group

\section{SESSION 1}

Brief theoretical explanation

$$
\begin{aligned}
& \text { Review of the } \\
& \text { evaluation rubric } \\
& \text { (professor together } \\
& \text { with the students) }
\end{aligned}
$$

Group critical

analysis exercise

(text selected by the professor)

\section{GROUP PRE-TEST}

Oral presentation of the exercise

\section{SESSION 2}

Group critical
analysis exercise
(text selected by
the professor)

Discussion in small groups

(3 people)

\section{GROUP POST-TEST}

Review of the exercise taking into account the contributions of the group

\section{SESSION 3}

Post-test self-perception questionnaire on critical thinking
Individual critical

analysis exercise.

(text selected by

the students)
Brief oral

presentation of

the exercise
INDIVIDUAL POST-TEST

Review of the exercise taking into account the contributions of the oral presentations

\section{SESSION 4}

Figure 1. Diagram of the implementation protocol 


\section{CONCLUSIONS}

After the implementation of this educational innovation project, it is possible to draw a number of preliminary conclusions. However, the research is currently in the process of further analyzing the results, so the final conclusions will be drawn in the near future.

During the sessions it has been detected that students were facing the theoretical analysis of texts in a rather detached way, however, in the $4^{\text {th }}$ session, the author and texts to be analyzed were chosen by each student and this was a key factor in the motivation shown during the exercise. If a slight improvement of students' skills can be detected, however, it is still early to conclude whether this improvement is significant and, if it is, to what is due.

Regarding the self-perception questionnaire on critical thinking skills, it has been observed that some students have decreased their self-perceived skill level of this competence at the end of the course. Beforehand, an improvement in self-perception was expected, but the opposite has been detected. As a preliminary conclusion, this decrease in self-perception can be associated with a greater awareness of what it means to make critical judgments. Being the students, at the end of the course, more conscious of the difficulties associated with the development of this transversal competence, they were able to self-assess it more critically.

\section{ACKNOWLEDGEMENTS}

This educational innovation project has been carried out as part of the assignments of the INEDInitiation to Educational Research course, held by the Institute of Educational Sciences of the Universitat Politècnica de València, Spain, during the 2018-2019 academic year.

\section{REFERENCES}

[1] Miranda Regojo, A.; Pina Lupiánez, R.; Casqueiro Barreiro, F.; Colmenares Vilata, S.; González De Mendoza Maruri, N. La crítica de arquitectura como modelo de investigación. 4IAU $4^{a}$ Jornadas Internacionales sobre Investigación en Arquitectura y Urbanismo. 2012.

[2] González A.C., "Criterios para el desarrollo del pensamiento crítico a través de textos literarios" in Revista Letras, ISSN 0459-1283, № 91, 2015.

[3] Lewis, A.; Smith, D. Defining higher order thinking in Theory into Practice 32, p. 131-137. 1993

[4] Halpern, D. An Introduction to Critical Thinking. New Jersey: LEA. 1984

[5] Paul, R.; Elder, L. La mini-guía para el Pensamiento crítico. Conceptos y herramientas. Fundación para el Pensamiento Crítico. www.criticalthinking.org

[6] Paul, R.; Elder, L. Estándares de Competencia para el Pensamiento Crítico. Estándares, Principios, Desempeño. Indicadores y Resultados. Con una Rúbrica Maestra en el Pensamiento Crítico. Fundación para el Pensamiento Crítico. www.criticalthinking.org

[7] Emily R. Lai. Critical Thinking: A Literature Review. Research Report. June 2011

[8] A. Gual Gual, E. A. Burgos Ramírez, S. Cuenca Almenar, "Pensamiento crítico en la construcción del conocimiento en la asignatura de Historia de la Ciencia y la Tecnología-Critical Thinking in the construction of knowledge in History of Science and Technology course" in II Congreso Internacional sobre Aprendizaje, Innovación y Competitividad (CINAIC 2013), november 6-8, 2013, Madrid, ESPAÑA

[9] L. Basco Prado, N. Rodríguez Avila, M. Puig Llobet, M. T. Lluch Canut, S. Fariñas Rodríguez, M. A. Giménez Lajara, "Escala de Autopercepción del Pensamiento Crítico en Alumnos de Enfermería-Critical Thinking Self-perception scale in Nursing Students", in III Congreso Internacional sobre Aprendizaje, Innovación y Competitividad (CINAIC 2015). Octubre 14-16, 2015, Madrid, ESPAÑA.

[10] Olivares Olivares, S.L.; López Cabrera, M.V. "Validación de un instrumento para evaluar la autopercepción del pensamiento crítico en estudiantes de medicina" in Revista Electrónica de Investigación Educativa Vol19, Num 2, 2017. 
[11] Pintrich, P.R., Smith, D.A.F., García, T., \& McKeachie, W.J. (1991). A manual for the use of the motivated strategies questionnaire (MSLQ). Ann Arbor, Ml: University of Michigan, National Center for Research to Improve Postsecondary Teaching and Learning.@

[12] Fernandez Núñez, L. ¿Cómo analizar datos cualitativos? In Butlletí LaRecerca. Universitat de Barcelona. Institut de Ciències de l'Educació, Octubre, 2006 